\title{
Patterns of CT referrals among physicians in the South-South region of Nigeria.
}

\author{
${ }^{1 *}$ O. F. Erondu, ${ }^{1}$ C. R. Okoro, ${ }^{2}$ J. I. Aniemeka and ${ }^{3}$ A. C. Ugwu \\ ${ }^{1}$ Department of Clinical Imaging, Image Diagnostics Port-Harcourt \\ ${ }^{2}$ Radiology Department, University of Port-Harcourt Teaching Hospital \\ ${ }^{3}$ Department of radiography, Nnamdi Azikiwe University, Nnewi Campus \\ *Corresponding author: okerons@yahoo.com, +2348023129893
}

\begin{abstract}
This study is aimed at determining the patterns of CT referral and hence its utilization by physicians in the South-South region of Nigeria within a 2year period. Despite its vast clinical applications, Computed Tomography scan is not readily available in developing countries like Nigeria, and awareness of its clinical applications based on anecdotal evidence is rather poor among physicians. A total of 450 scans were referred made up of 273 males (60.66\%) and 177 females (39.33\%).Majority of patients were within the age range of $41-50$ years representing $20.4 \%$ of all referrals. Brain CT is the most frequently requested with intracranial hematoma as the most common finding. The majority of all scans taken within this period were referred by neurosurgeons $43.1 \%$ (194), followed by general practitioners $33.33 \%$ (150). Analysis of clinical indications showed hematoma to be the highest reason for Brain CT referrals $17.4 \%(47$; thoracic mass for chest CT, 37.5\% and abdominal pain (21.3\%) for Abdominal CT referral. Abnormal findings were identified in $25 \%$ of all brain CT's performed and $40 \%$ of all other cases studied for the rest of the body. The study showed a relatively poor referral rate of CT among physicians in the South- South region of Nigeria. This study recommends proper sensitization of doctors on the wide clinical applications of CT, an improved Health insurance scheme to ensure better access to modern diagnostic tools by patients, as well as training of radiographers and doctors on the clinical utilization of CT scan results.
\end{abstract}

Keywords: Patterns, CT referrals, Physicians, Nigeria

\section{INTRODUCTION:}

Since its introduction in the 1970s, computed tomography (CT) has been shown to have wide applications within all the radiological subspecialties [Lowe and Kay, 2006]. Indeed, so successful has CT become, that it has effectively replaced many other radiological procedures (e.g. lymphangiography), catheter arterial and venous angiography of the brain and spine[Zeman et al., 1995]

Furthermore, as CT becomes more and more widely accepted, it has become a primary imaging technique in its own right. New applications and clinical roles for CT have emerged in the last few years including $\mathrm{CT}$ angiography, pulmonary embolism detection, the diagnosis of abdominal pain and appendicitis and the investigation of renal colic [Van Erkel et al., 1996; Mindelzun and Jeffrey 1997]. The use of multidetector techniques and improved multiple reconstructive algorithms have introduced newer opportunities in the use of computed Tomography for diagnosis of pathologies of the brain, spine, orbits, fractures and vascular system. [Teasdale, 2007] Although there is still a place for radiologists with particular expertise in the technical aspects of CT and the interpretation of cross- sectional anatomy, it is now virtually impossible to practise radiology in any of the subspecialties without access to CT and a fair understanding of its capabilities. Despite its advantages, attempts have been made to re-evaluate the use of CT, particularly in terms of cost and radiation dose [Saini et al., 2001], and costeffectiveness in specific diagnostic settings [Romero et al. 2008].There is ample evidence based on studies in other countries, which have shown that the judicious application of diagnostic tests such as CT and ultrasound and MRI results in a more costeffective strategy than the clinical exam [Axelrod et al., 2000; Fuji et al., 2000; Pena et al., 2000; Pena et al. , 1999) .In spite of this evidence, the results of a cost-effectiveness study cannot be extrapolated readily, considering cost differences in different 
health systems [Bryan and Brown, (1998); Drummund e.t al. ,1992). In recent years, we are witnessing a crisis in the health care systems around the world as different countries are faced with the need to control health care costs while attempting to provide high quality care. One of the main reasons for the increase in health expenditure is the high cost of medical diagnostics procedures such as computerized tomography (CT) and magnetic resonance imaging (MRI) [Oppenheimer and Avni 2010] and there is obvious need to ensure that the benefits derivable justify their cost.

Despite its vast clinical applications, this modality is not readily available in developing countries like Nigeria, and awareness of its clinical applications based on anecdotal evidence is rather poor among general practice physicians and health-care providers. Nigeria is a country of over 120 million people with 36 states and a federal capital territory. Less than thirty (30) CT machines are in active use in Nigeria as at August 2009 [NNRA, 2009] with 65\% owned by the Federal government, $5 \%$ by State government and $30 \%$ by private establishments. This difference in acquisition could be attributed to high cost of machines, maintenance, and poor awareness of its multifunctional attributes. This study is aimed at determining the patterns of referral and hence the utilization of this very important imaging modality by physicians in the South-South region of Nigeria.

\section{MATERIALS AND METHODS:}

A non- experimental retrospective design was adopted. Secondary data which includes all referral forms and results (radiological reports) of the CT investigations were obtained for the study. A sample size of four hundred and fifty (450) records of patients who were referred for CT were obtained from Image
Diagnostics Port-Harcourt within June 2007- June 2009. All the referring physicians work and reside in the South-South geopolitical region. Approximately 2 million people reside within the South- south district of Nigeria.

Permission to peruse the records was obtained from the Research and Human Ethics committee of Image Diagnostics.

The data was collected from the referral forms and information obtained include demographic information (such as age, sex), specialty of doctor initiating the referral, the reason for the referral, the provisional diagnosis and the radiological diagnosis.

All referral forms for this period were collected, and data entry and analysis were performed using epi info 6.0 and SPSS-PC statistics software version 14, to carry out standard statistical tests such as Chisquare and t-tests). A $p<0.05$ was used as criteria for statistical significance.

In the 48-month period, a total of 450 scans were performed. Of these, males represented $60.66 \%$ (273) while females represented $39.33 \%$ (177) of the total sample size as seen in table 1. Furthermore, the males constitute a greater population in all ages except for the ages ranging from 21- 30years. However CT referrals for patients within $41-50$ years, had the highest occurrence $20.4 \%$ (92)

A total of ten (10) types of scans were identified in this study, and out of these classes, brain CT had the highest referral rate $63.8 \%$ (287) as deduced from table 3. However CT scan of the orbit constituted the lowest referrals $1.11 \%$ (5) from clinicians.

\section{DATA PRESENTATION:}

Table 1: Age and sex Distribution of patients

\begin{tabular}{|l|l|l|l|l|}
\hline Age (Yrs) & Frequency & & Percentage (\%) & \\
\hline & Male & Female & Male & Female \\
\hline$<1-10$ & 26 & 20 & 56.52 & 43.48 \\
\hline $11-20$ & 24 & 17 & 58.54 & 41.46 \\
\hline $21-30$ & 18 & 23 & 43.90 & 56.10 \\
\hline $31-40$ & 48 & 30 & 61.54 & 38.46 \\
\hline $41-50$ & 54 & 38 & 58.70 & 41.30 \\
\hline $51-60$ & 40 & 16 & 71.43 & 28.57 \\
\hline $61-70$ & 30 & 18 & 62.50 & 37.50 \\
\hline 71 and above & 33 & 15 & 68.75 & 31.25 \\
\hline & 273 & 177 & 60.20 & 39.80 \\
\hline
\end{tabular}


Table 2; Patterns of referral according to body Parts

\begin{tabular}{|l|l|l|}
\hline Examination & Frequency & Percentage (\%) \\
\hline Brain & 287 & 63.78 \\
\hline Orbit & 5 & 1.11 \\
\hline Neck & 17 & 3.78 \\
\hline Chest & 40 & 8.88 \\
\hline Abdomen & 61 & 13.56 \\
\hline Pelvis & 7 & 1.55 \\
\hline Spine & 25 & 5.56 \\
\hline Sinuses & 8 & 1.76 \\
\hline & 450 & 100.00 \\
\hline
\end{tabular}

Table 3: Distribution of referring clinicians according to specialty

\begin{tabular}{|l|l|l|}
\hline Referring Clinicians & Frequency & Percentages(\%) \\
\hline Neurosurgeons & 194 & 43.11 \\
\hline Paediatricians & 12 & 2.68 \\
\hline General ractitioners & 150 & 33.33 \\
\hline Opticians & 8 & 1.78 \\
\hline Psychiatrics & 20 & 4.44 \\
\hline ENT & 18 & 4.00 \\
\hline Gastroenterologists & 14 & 3.11 \\
\hline Orthopaedics & 14 & 3.11 \\
\hline Self & 20 & 4.44 \\
\hline & 450 & 100 \\
& & \\
\hline
\end{tabular}

Table 4A:

A. Indications for Brain CT scan referrals

\begin{tabular}{|l|l|}
\hline Reason for referral & Frequency \\
\hline CSOM & 5 \\
\hline Embolic Stroke & 3 \\
\hline Multifocal contusion & 42 \\
\hline Brain tumor & 15 \\
\hline ? SOL & 43 \\
\hline Hydrocephalus & 12 \\
\hline Hematomas & 47 \\
\hline Encephalopathy & 8 \\
\hline Brain metastasis & 6 \\
\hline \#Base of the skull & 7 \\
\hline CVA & 24 \\
\hline Intracranial abscess & 5 \\
\hline Headache & 17 \\
\hline Meningitis & 5 \\
\hline Seizure & 28 \\
\hline
\end{tabular}

Table 4B: Orbit

\begin{tabular}{|l|l|}
\hline Reason for referral & Frequency \\
\hline ? Orbital mass & 2 \\
\hline Proptosis & 3 \\
\hline & 5 \\
\hline
\end{tabular}

Table 4C: Abdomen

\begin{tabular}{|l|l|}
\hline Reasons for referral & Frequency \\
\hline Abdominal pain & 13 \\
\hline Gastrointestinal disease & 5 \\
\hline Pancreatic disease & 10 \\
\hline Urolithiasis & 2 \\
\hline Hepatobiliary disease & 10 \\
\hline Intrabdominal mass & 8 \\
\hline Abdominal fullness & 3 \\
\hline Abdominal neoplasm & 3 \\
\hline Others & 7 \\
\hline & 61 \\
\hline
\end{tabular}

Table4 D. Chest

\begin{tabular}{|l|l|}
\hline Reason for referral & Frequency \\
\hline Thoracic mass & 15 \\
\hline Pleural effusion & 6 \\
\hline Hemoptysis & 3 \\
\hline Acute respiratory difficulty & 3 \\
\hline Chest pain & 6 \\
\hline Metastasis & 7 \\
\hline & 40 \\
\hline
\end{tabular}

Table 4E. Neck

\begin{tabular}{|l|l|}
\hline Reason for referral & Frequency \\
\hline ? Ca Larynx & 2 \\
\hline ? Cervical fractures & 10 \\
\hline Respiratory difficulty & 3 \\
\hline Parathyroid mass & 2 \\
\hline & 17 \\
\hline
\end{tabular}

Table 4F. Sinuses

\begin{tabular}{|l|l|}
\hline Reason for referral & Frequency \\
\hline Recurrent nasal discharge & 2 \\
\hline Sinusitis & 4 \\
\hline Neoplasm & 2 \\
\hline & 8 \\
\hline
\end{tabular}

Table 4G. Lumbosacral spine

\begin{tabular}{|l|l|}
\hline Reason for referral & Frequency \\
\hline Slipped disc & 14 \\
\hline Paraesthesia & 7 \\
\hline Low back pain & 2 \\
\hline RTA & 2 \\
\hline & 25 \\
\hline
\end{tabular}


Table 4H: Pelvis

\begin{tabular}{|c|c|c|}
\hline \multicolumn{2}{|l|}{ Reason for referral } & Frequency \\
\hline \multicolumn{2}{|l|}{ Osteoarthritis } & 3 \\
\hline \multicolumn{2}{|l|}{ Suprapubic pain } & 1 \\
\hline \multicolumn{2}{|l|}{ Bladder mass } & 4 \\
\hline \multicolumn{2}{|l|}{ 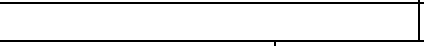 } & \\
\hline BODY PART & $\begin{array}{l}\text { NORMAL } \\
\text { FINDINGS }\end{array}$ & $\begin{array}{l}\text { ABNORMAL } \\
\text { FINDINGS }\end{array}$ \\
\hline Brain & 105 & 182 \\
\hline Orbit & 2 & 3 \\
\hline Neck & 4 & 8 \\
\hline Chest & 25 & 15 \\
\hline Abdomen & 23 & 38 \\
\hline Pelvis & 7 & 10 \\
\hline Spine & 6 & 13 \\
\hline Sinuses & 5 & 8 \\
\hline
\end{tabular}

The majority of all scans taken within this period were referred by neurosurgeons $43.1 \%$ (194). This is followed by general practitioners which had a significant referral rate $33.33 \%$ (150). Self referral CT investigations were seen to have an appreciable rate in this study, $4.4 \%$ (20).

The most frequent clinical indication for brain $\mathrm{CT}$ is hematomas $17.4 \%$ (47) and the least, embolic stroke $1.03 \%$ (3). Abdominal pain (21.3\%) was the most frequent reason for Abdominal CT referral while the least from urolithiasis 3.3\% (2). Suspected cervical fracture was the most frequent reason for Neck CT referral (58.8\%).

Approximately $40 \%$ of all referrals showed abnormal findings for brain CT with $25 \%$ abnormal outcomes.

\section{DISCUSSION:}

Physicians are often required to make decisions regarding referrals for $\mathrm{CT}$. This decision is based on multiple factors such as medical history, physical exam, patients request and other medical considerations [Shrimpton and Wall ,1995]. Other considerations may be the risk involved when contrast agents are indicated, exposure to radiation, the cost of the test. In our study, a total of four hundred and fifty patients were referred for CT scan of several body parts. This number if compared to the population and number of physicians indicate a poor referral rate from physicians within the 2-year period under study. This finding is at variance with a recent research which shows a rapid increase of $\mathrm{CT}$ referrals in the United Kingdom and other European countries [Shrimpton and Wall 1995]. The difference may well be due to poor knowledge of the potentials of CT, compliance and ability to pay. In recent times, brain $\mathrm{CT}$ has been the most frequently requested part of the body in the world (JAMA 1982). This is in agreement with our study as brain CT amounts to $63.8 \%$ of the total referrals in this study. The greater occurrence of haematomas especially due to RTA was identified in this study. This is majorly due to the widespread use of motorbikes for commercial transport purposes within the period of this study. This does not agree with a study from Israel by Shvartzman et al.. (2010) which shows that headache is the main clinical indication for brain CT.. Out of the 287 brain CT cases, 182 (63.4\%) result showed abnormal findings which majorly corresponds to the pre- CT diagnosis and 105 (36.6\%) showed normal findings.

A total of $42(40.0 \%)$ of the normal findings were of pre-CT diagnosis for seizure disorders.

Abdominal CT is also known to be among the frequently referred modality which corresponds to our study as it followed after brain CT. Acute abdominal pain is a common presenting symptom in the emergency department and has many underlying causes [Mayo-Smith et al., 2002].

Our study is in agreement with another study in the UK by Levine (1985), Although abdominal radiography has traditionally been considered an essential parts of the work-up in patients with acute abdominal pain, the results are often non specific [Mc Cook et al. , 1982; Marineck, 2002]. The majority of cases referred abdominal CT were emergencies especially when ultrasound is not very definitive in its findings. In this study, 38(62.3\%) abdominal CT's show abnormal findings while 23(37.7\%) showed normal findings. Cases for abdominal pain yielded the highest occurrence of normal findings 10(43.5\%). Orbital CT scans as well as that of the pelvic region are not commonly referred, as this may be attributed to radiation protection measures since other investigative modalities could be employed. However, most abdominal CTs include a significant portion of the pelvic region [Di Marco and Renston, 1994].

Computed tomography (CT) scans are used extensively to investigate chest disease because of their cross-sectional perspective and superior contrast resolution compared with chest radiographs. These advantages lead to a more accurate imaging assessment of thoracic diseases [Simpson and Hartrick, 2007]. 
However in our study, CT for thoracic masses constituted the highest percentage of the results having normal findings $11(44.0 \%)$. It is however noted that these patients had undergone chest $\mathrm{x}$-ray. This disparity between the chest $x$-ray and CT findings may be attributed to low index of suspicion based on plain film report.

In this study, it was observed that out of all CT, 177 cases that turned out normal findings, 100 (56.5\%) were referred by general practitioners. This is attributed to poor knowledge of the indications for CT scanning similar to a previous study [Simpson and Hartrick, 2007].

This can be improved if there is for good communication between the radiologist, specialist doctors as well as general practitioners in deciding the appropriateness of a referred CT investigation.

\section{CONCLUSION:}

In this study, CT referral rate is low as compared to other countries especially in UK, Europe and Australia. This may be due a perceived lack of awareness of the potential clinical benefits and diagnostic capabilities among physicians in this cohort. Although the cost of CT investigations are relatively high, poor access to health insurance in Nigeria, implies that most patients pay directly for the test. This may be a contributing factor to the low referral rate of physicians who obviously would consider affordability of their patients.

This study recommends proper sensitization, through seminars to educate doctors and health-care providers on the wide clinical applications of CT. An improved Health insurance scheme would ensure better access to modern diagnostic tools by patients who would no longer bear the cost directly.

Finally, with high referrals for CT brain, improved training of radiographers and doctors is needed on the clinical utility of computed tomography.

\section{REFERENCES:}

Axelrod DA, Sonnad SS, Hirschl RB (2000). An economic evaluation of sonographic examination of children with suspected appendicitis.

J Pediatr Surg 35: 1236-41

Bryan S, Brown J (1998). Extrapolation of costeffectiveness information to local settings. J Health Serv Res Policy 3:108-12.
Di Marco AF, Renston JP (1994). In search of the appropriate use of chest tomography. Chest 106 : 323-3

Drummond MF, Bloom BS, Carrin G, Hillman AL, Hutchings HC, Knill-Jones RP, et al. (1992). Issues in the cross-national assessment of health technology. Int J Technol Assess Health Care 8:671-82. (crossref)

Fujii Y, Hata J, Futagami K, Hamada T, Mitsuoka $\mathrm{H}$, Teramen K, et al., (2000). Ultrasonography improves diagnostic accuracy of acute appendicitis and provides cost savings to hospitals in Japan. J Ultrasound Med.19:409-14. (cross-ref)

Javier Romero, Álvaro Sanabria, Miguel Angarita, Juan Carlos Varón, (2008). Cost-effectiveness of computed tomography and ultrasound in the diagnosis of appendicitis. Biomédica 28(1):139-47 Bogotá

Levine MS, (1985). Plain films diagnosis of the acute abdomen. Emerg Med Clin North AM 3: 541-562

Lowe A S and Kay C L( 2006). Recent developments in CT. A Review of the clinical applications and advantages of multi-detector computed Tomography. Imaging 18:62-67

Marineck B (2002). Non-Traumatic abdominal emergencies: acute abdominal pain diagnostic strategies. Eur Radiol 12: 2136-2150

Mayo-Smith WW, Murphy BL, Reineit SE, Cronan JJ, Ahn Sun Ho, (2002). Acute non-traumatic abdominal pain in adult patients: Abdominal radiography compared with CT evaluation. Radiology 225: 159-164

Mc Cook TA, Ravin CE, Rice RP (1982). Abdominal radiography in the emergency department: a prospective analysis. Ann Emerg Med; 11:7-8

Mindelzun R E, Jeffrey R B, (1997). Unenhanced Helical CT for evaluating acute abdominal pain; a little more cost, a lot more information. Radiology 205: $43-45$.

Nigerian Nuclear Regulatory Authority (2009). Feedback from survey and inspection of Radiology Facilities in Nigeria. NNRA bulletin

NIH Consensus Development Panel. (1982) Computed tomographic scanning of the brain. JAMA. 247, 19551958

Oppenheimer J, Avni Y. Population characteristics as a predominant factor in radiology utilization ( Personal communication) in Shvartzman P et al., (2010). Brain computerized tomography utilization by primary care physician. Family Medicine on-line. Accessed Sept $10^{\text {th }}$.

Pena BM, Taylor GA, Fishman SJ, Mandl KD, (2000). Costs and effectiveness of ultrasonography and limited computed tomography for diagnosing appendicitis in children. Pediatrics.106:672-6. (cross-ref) 
Pena BM, Taylor GA, Lund DP, Mandl KD, (1999). Effect of computed tomography on patient management and costs in children with suspected appendicitis. Pediatrics. 104:440- 446.

Saini S, Sharma R, Levine LA, Barmson RT, Jordan PF, Thrall JH (2001) Technical cost of CT examinations. Radiology 218: 172-175

Shrimpton PC, Wall BF, (1995). The increasing importance of x-ray computed tomography as a source of medical exposure. Radiat Prot Dosim ; 57: 413-419

Shvartzman $P$, Sherf $M$, Friger $M$, Tabenkin $H$, Anat Neville,( 2010). Brain computerized tomography utilization by primary care physician . Family Medicine on-line. utilization by primary care physician. Family Medicine on-line. Accessed on Sept $10^{\text {th }}$.
Simpson, G, Hartrick GS. (2007). Use of thoracic computed tomography by general practitioners. MJA Med J. Aust ; 187(1) : 43-46

Sturman MF, (1991). Medical imaging in acute abdominal pain. Compr Ther; 17: 15-21

Teasdale E, ( 2007). Multidetector CT: new horizons in neurological imaging. Imaging 19, 153-172

Van Erkel A R, Van Rossum A B, Bloem JL, Kievit J, Pattynama PM, (1996). Spiral CT angiography for suspected pulmonary emboli; a cost effective analysis. Radiology 201:29 - 36

Zeman R K, Silverman PM, Vieco PT, Costello P, (1995). CT angiography. AJR Am J Roentgenol 165: 10791088. 